\title{
SELOS E APELOS: FABRICAÇÃO DA IMAGEM DE AÇÚCAR "VERDE” E AGENDAMENTO
}

\author{
Seals and appeals: "green" sugar image construction and \\ agenda setting
}

\author{
Sellos y apelaciones: construcción de la imagen de azúcar \\ "verde" y agenda
}

\author{
Ivan Paganotti \\ Universidade de São Paulo, São Paulo, Brasil. \\ Doutor em Ciências da Comunicação pela Escola de Comunicações e Artes da Universidade de São Paulo. \\ Pesquisador do grupo de estudos MidiAto/ECA-USP. \\ E-mail: ivanpaganotti@gmail.com

\section{Mariana de Toledo Marchesi} \\ Universidade de São Paulo, São Paulo, Brasil. \\ Mestre em Ciências da Comunicação pela Escola de Comunicações e Artes da Universidade de São Paulo. \\ Pesquisadora do Centro de Pesquisas Atopos. \\ E-mail: nanatm@gmail.com
}

RESUMO Este artigo analisa a construção da imagem de marcas sustentáveis de açúcar a partir das informações e representações imagéticas utilizadas nas embalagens para o consumidor. A representação da consciência socioambiental diverge entre as empresas avaliadas: União, Native e Guarani, que se baseiam em estratégias diferentes de agendamento dos comportamentos dos consumidores, e só as duas primeiras fundamentam sua imagem em selos e certificados de instituições que avaliam a gestão sustentável dos produtos.

PALAVRAS-CHAVE Sustentabilidade, Greenwashing, Publicidade, Açúcar, Comunicação.

ABSTRACT This article examines how sustainable sugar brands build their image, using the information and imagery representations displayed on small packages offered to consumers. Representation of social and environmental awareness differs among the evaluated companies: União, Native and Guarani use different strategies to influence consumers' behaviors, and only the first two base their image in stamps and certificates from institutions which evaluate sustainable practices of production.-

KEYWORDS Sustainability, Greenwashing, Advertising, Sugar, Communication.

RESUMEN En este trabajo se estudia la construcción de la imagen de marcas sustentables de azúcar basándose en las informaciones y representaciones en los embalajes disponibles al consumidor. La representación de la consciencia social y ambiental es diferente entre las empresas evaluadas: União, Native y Guarani, que utilizan distintas estrategias para influenciar el comportamiento de los consumidores, y solamente las dos primeras fundamentan su imagen en sellos y certificados de instituciones que evalúan su gestión sustentable.

PALABRAS CLAVE Sustentabilidad, Greenwashing, Publicidad, Azúcar, Comunicación.

Este artigo inédito está baseado em resultados apresentados pelos autores no Comunicon-2012. 


\section{INTRODUÇÃO: CARTAZES AMBIENTALISTAS RECICLADOS}

Nas últimas décadas, a "sustentabilidade" saltou dos relatórios de pesquisadores e dos documentos de organizações internacionais preocupadas com a preservação ecológica para os cartazes de ambientalistas - e, nos últimos anos, estampa também as embalagens de itens que buscam responder à demanda por produtos em equilíbrio com a natureza. O conceito foi difundido pela ex-primeira-ministra da Noruega, Gro Harlem Brundtland, em 1987 no informe "Nosso futuro comum”, resultado da Comissão Mundial sobre o Meio Ambiente e o Desenvolvimento, da Organização das Nações Unidas (ONU). O Informe Brundtland defendia um desenvolvimento sustentável, reconhecendo a necessidade de harmonizar as relações entre a produção humana e o equilíbrio ambiental para permitir o desenvolvimento econômico, social e ambiental das gerações atuais e futuras (Dias, 2009, p. 31).

A difusão recente desse conceito se torna evidente no contraste das respostas fornecidas por empresários a enquetes realizadas pela Confederação Nacional da Indústria (CNI) no curto intervalo entre 2005 e 2010. Questionados sobre os motivos que os levaram à adoção de medidas de gestão ambiental, os motivos principais apresentados variaram significativamente entre os anos em que essa pesquisa foi conduzida pela CNI (Gráfico 1).
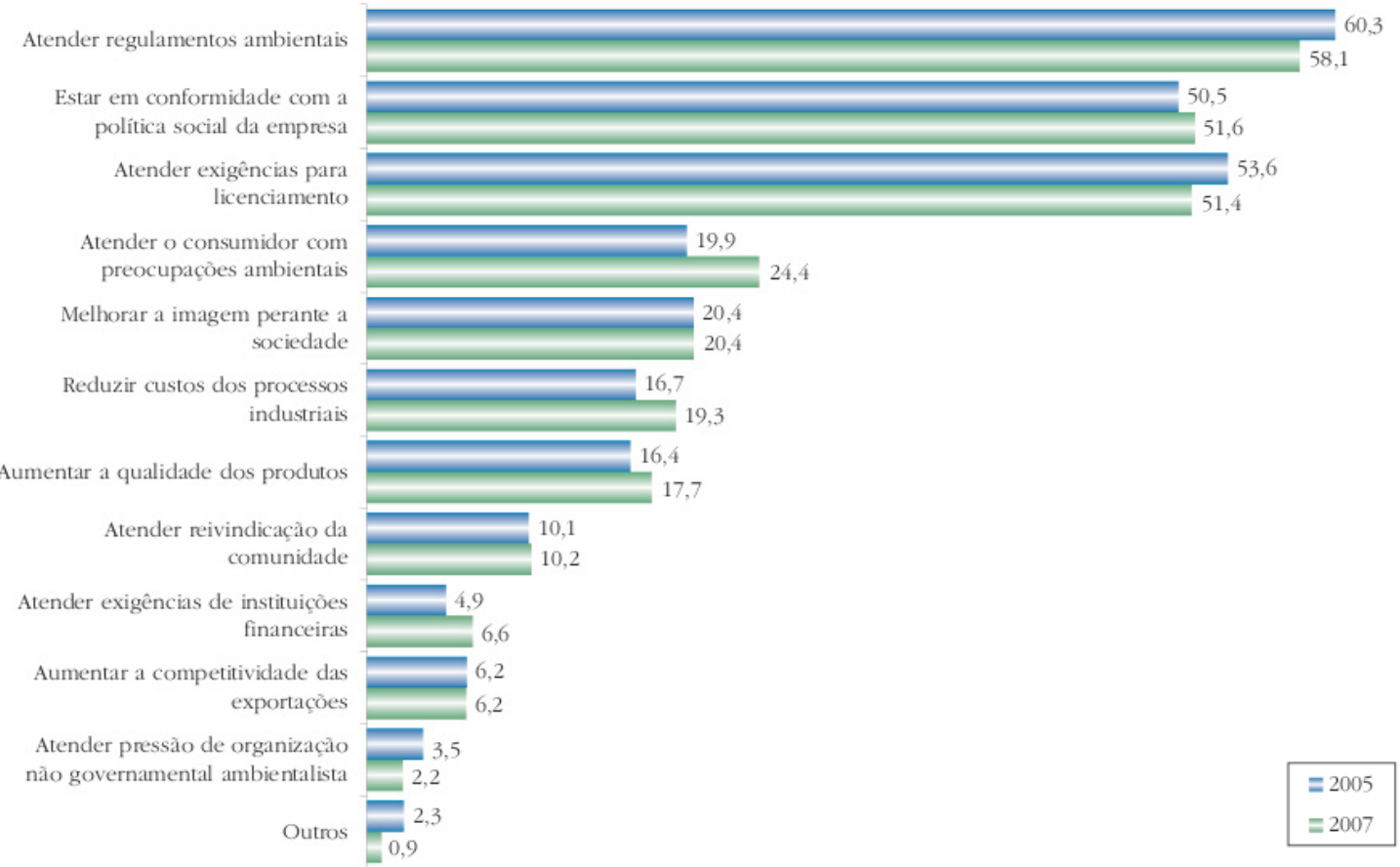

Gráfico 1. Principais razões para a adoção de medidas gerenciais associadas à gestão ambiental (2005/2007).

Fonte: CNI (2007, p. 4). 


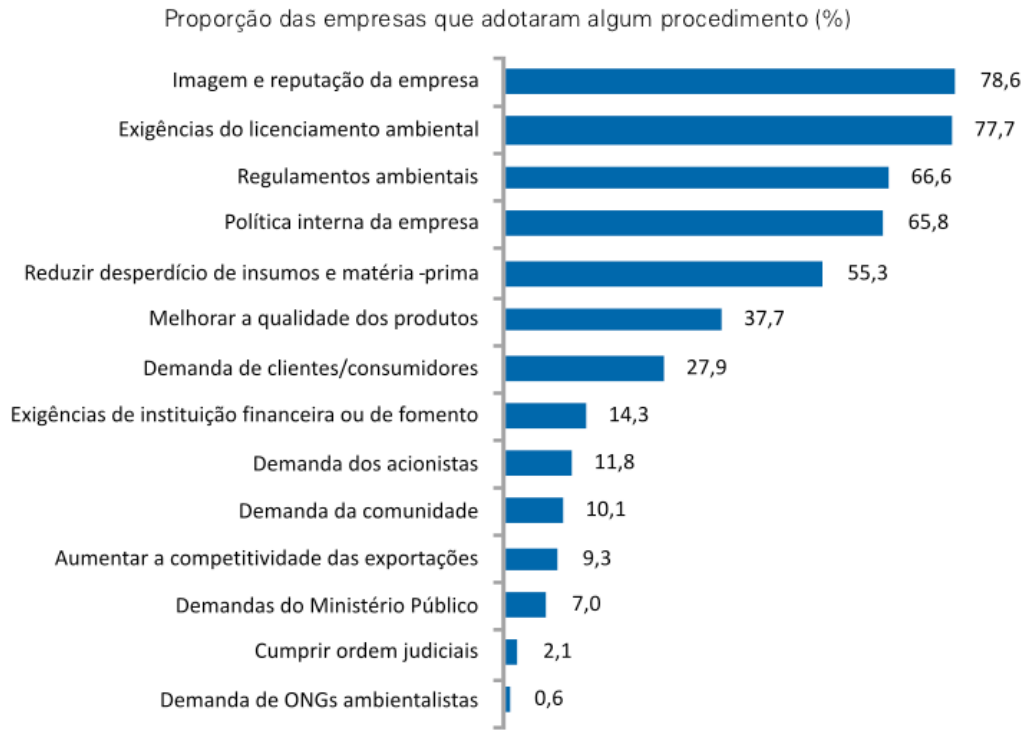

Gráfico 2. Principais fatores para a adoção de procedimentos de gestão ambiental (2010). Fonte: CNI (2010, p. 3)

Em 2005, as principais justificativas para a preocupação ambiental do empresariado envolviam a legislação nacional - para "atender regulamentos ambientais" (60,3\%) ou "atender exigências para licenciamento" (53,6\%) - ou encontravam motivação nas suas próprias normas internas - para "estar em conformidade com a política social da empresa” (50,5\%). "Atender o consumidor com preocupações ambientais" $(19,9 \%)$ e "melhorar a imagem perante a sociedade" $(20,4 \%)$ seguiam em um distante segundo plano, visto que a preocupação maior envolvia seguir normas internas ou legais. Entretanto, somente cinco anos depois, em 2010, nota-se uma inversão, pois a preocupação com a imagem social da empresa se tornou uma questão mais evidente até mesmo do que as exigências legais e a obediências às práticas internas: "imagem e reputação da empresa" (78,6\%) superaram as ainda importantes "exigências do licenciamento ambiental" (77,7\%), "regulamentos ambientais" (66,6\%) e a "política interna da empresa" (65,8\%).

Essa pesquisa evidencia a percepção bastante difundida de que os consumidores preferem empresas que adotem a gestão ambiental de sua cadeia produtiva. Dias (2009, p. 139) avalia que muitos consumidores inclusive consideram justo arcar com parte dos custos de práticas social e ambientalmente adequadas, mesmo que elevem os preços de suas mercadorias. Esse novo nicho de mercado mostrou-se fértil para ampliar os ganhos e para promover a imagem de empresas conscientes, agregando valor a seu produto e marca (Srour, 2008, p. 66) ao criar uma "vantagem competitiva” em relação aos competidores que não adotam a gestão ambiental (Silva, 2011, p. 101).

Para verificar e atestar as práticas adequadas e premiar as companhias que não adotam o verde só como jogada de marketing, proliferam os certificados e selos que apresentam ao consumidor, inclusive estampado nas próprias mercadorias, a doação de parte da renda para organizações que defendem causas socioambientais, a preocupação de empresas com sua cadeia produtiva ou com os resíduos de seus produtos (Louette, 2007). Nesse sentido, este trabalho procura analisar a imagem construída por três marcas de açúcar bastante difundidas - União, Native e Guarani 
- e distribuídas ao consumidor final na forma de pequenos sachês disponíveis gratuitamente em estabelecimentos alimentícios, avaliando as estratégias adotadas por cada empresa para aliar-se a discursos e práticas de sustentabilidade.

\section{Greenwashing: embalagem verde aquém da certificação}

Se as práticas sustentáveis de uma empresa tornaram-se um problema tão importante que pode levar consumidores a usar essa questão como fator decisivo na compra de certos produtos ou serviços, as empresas devem se preocupar em tornar evidentes suas iniciativas de gestão ambiental para atrair esse perfil de consumidor consciente - e para evitar a perda de sua clientela para outros concorrentes que saibam construir um perfil tão "verde" quanto seus consumidores desejam. Não basta mais somente evitar a publicidade negativa blindando as empresas de casos de desastres ambientais, mostrando o respeito em relação às leis ambientais vigentes. Torna-se necessário adotar certificações complementares, mais rígidas do que a legislação, mas que demonstrem ao público um engajamento prático (ou ao menos retórico) com a preocupação ambiental. Ainda que permaneçam normas de "adesão voluntária” (Louette, 2007, p. 177), acabam por se tornar imperativas em um mercado competitivo que valoriza a imagem de uma marca atrelada à preocupação socioambiental.

Atualmente, "os processos produtivos antes conhecidos por alguns dentro das empresas, sob certos aspectos, popularizam-se” (Dias, 2009, p. 59), seja por meio de denúncias midiáticas ou, preventivamente, por meio da publicidade institucional que abre à fiscalização de seu público sua cadeia de produção. Ainda assim a distância entre os consumidores e os locais de manufatura ou extração dificulta "a percepção dos efetivos impactos sociais e ambientais" da cadeia produtiva, e acaba por incentivar um difuso "fetichismo da natureza” (Guimarães Jr., 2011, p. 259): o público sente uma incerta necessidade de diminuir a degradação resultante de seu consumo, e responde positivamente às ofertas de produtos de empresas com preocupações ambientais. Nesse cenário, consolidou-se uma procura - por parte de empresas, principalmente em resposta à demanda de seus públicos - por certificados que garantem as corretas e verdadeiras práticas de gestão socioambiental, agindo como representantes do interesse do público em assegurar o controle de suas pegadas ecológicas sem comprometer seu contínuo desejo por novos produtos:

Os chamados selos ecológicos se referem à identificação dos produtos por meio de um selo ou etiqueta, emitidos por entidades, organizações comerciais ou não governamentais, reconhecendo que o produto cumpriu determinados padrões ambientais previamente estabelecidos. A adesão aos selos verdes é voluntária; eles estão mais estabelecidos nos países onde os consumidores têm maior consciência ecológica. (Dias, 2009, p. 60)

Esse carimbo age como passaporte de acesso a alguns públicos sofisticados, em mercados preocupados com o impacto ambiental do consumo, e funciona como uma garantia para o consumidor que "não possui meios de saber se as empresas realmente cumprem com o que afirmam na propaganda” (Dias, 2009, p. 151). De modo geral, os certificados avaliam a gestão da cadeia produtiva, desde a extração da matéria-prima até o descarte final, oferecendo ao consumidor - que não têm tempo de verificar pessoalmente as pretensas preocupações 
ambientais de seus produtos de preferência - uma prova de que o discurso verde vai além da coloração amigável das embalagens: "um produto será ecológico quando cumprir as mesmas funções dos produtos equivalentes, mas causando um prejuízo perceptivelmente menor ao longo de todo o seu ciclo de vida, tanto na produção como no consumo quanto na eliminação final”. (Dias, 2009, p. 144)

Essa certificação evidencia, por contraste, os casos em que a imagem ecológica se traduz simplesmente no uso de materiais extraídos da natureza, "ignorando que o que o habilitaria como 'ecologicamente correto' seria, ao contrário, a redução da pressão sobre os ecossistemas” (Guimarães Jr., 2011, p. 237), ou seja, justamente o manejo mais cuidadoso desses recursos. Esse "posicionamento ecológico com reflexos emocionais" pretende associar o consumo de um produto com "a experiência sensorial de contato com a natureza" (Dias, 2009, p. 149). Cenários idílicos e verdejantes reforçariam as expectativas dos consumidores ao projetar uma imagem de conforto, qualidade e preocupação ambiental, mesmo sem embasamento em práticas que realmente diminuam o impacto do consumo. Nesses casos, Guimarães Jr. (2011, p. 237) critica o fato de que o discurso sustentável pode ser usado somente para "estimular o consumo e legitimar uma produção", sem "promover uma reflexão profunda acerca das práticas e valores sobre os quais se apoiam as sociedades contemporâneas".

A necessidade de selos ecológicos, entretanto, parte de uma abordagem mais "racional" do que emotiva, na avaliação de Dias (2009, p. 149), "proporcionando informações predominantemente técnicas ao consumidor, mostrando que, durante o seu ciclo de vida, o produto gera baixo impacto negativo ao meio ambiente". Com isso, a certificação ambiental procura facilitar o contato do consumidor com as informações presentes nos relatórios e balanços produzidos pelas empresas preocupadas com a sua cadeia produtiva, sintetizando suas ações em um símbolo facilmente apreensível e padronizável - além de verificável e confiável - como os selos de certificação:

Mais do que os balanços destacam-se outros meios alternativos inexplorados pela maioria das grandes empresas, como rótulos, selos e etiquetas indicativas de ações, validação externa dos investimentos via parcerias com ONGs que têm credibilidade pública, informações distribuídas nos pontos de venda e até certificações do governo ou de entidades públicas. (Echegaray, 2009, p. 242)

Por outro lado, como o predomínio dos vínculos emotivos podem ser mais importantes para a atração do consumidor, é necessário mesclar as estratégias racionais que certificam as práticas sustentáveis com as sensações de contato e preocupação com a natureza: "a dimensão emocional aproxima o cliente da marca, e a dimensão racional consolida a fidelidade deste, pois fundamenta a sua escolha perante outros membros da sociedade”. (Dias, 2009, p. 150)

Contudo, a promoção de iniciativas pontuais de redução de impacto ambiental ou a construção de uma imagem ecologicamente preocupada não são suficientes se a cadeia produtiva como um todo não for levada em consideração. Nesses casos em que a fachada de uma empresa pretende passar por uma "lavagem verde" - tradução literal de greenwashing -, procura-se desviar a atenção do público por meio do spin, enfatizando alguns projetos específicos que tentem limpar a imagem de companhias que ainda não apresentam uma preocupação 
sistemática sobre seus impactos ambientais em uma perspectiva mais ampla. Entretanto, essa estratégia envolve um risco, pois o público detém outras formas de fiscalizar a amplitude reduzida dessas iniciativas e compara a publicidade favorável com o envolvimento de empresas em denúncias de desastres ecológicos. A ONG Greenpeace ${ }^{1}$ já criou um antiprêmio para destacar essas iniciativas com o sugestivo nome de "Emerald Paintbrush" ("Pincel Esmeralda") para alertar os consumidores sobre a construção de imagens "verdes" sem práticas substanciais que fundamentem essa pretensão ecológica (Greenpeace, 2008). Além da "perda de confiança do consumidor” (Dias, 2009, p. 142), “campanhas consideradas 'irresponsáveis', abusivas ou com conteúdo claramente voltado ao greenwashing correm o risco não só de causar danos à imagem das empresas, mas de fazer que estas sejam alvo de boicotes e perseguições legais” (Santos, 2009, p. 157).

Para além da quase onipresente representação do imaginário "verde" nas embalagens de seus produtos, as empresas assumem graus distintos de responsabilidade pela sustentabilidade de suas cadeias de produção. Com isso, o consumidor é posicionado como juiz das melhores práticas de gestão ambiental, deixando ao critério do cliente o que a lei e o cidadão não conseguem fiscalizar corretamente - ampliando o fardo cognitivo da escolha de consumidores, que agora devem levar em consideração também critérios de responsabilidade ecológica e social, estampados e assegurados pela certificação socioambiental.

Do lado do consumidor, divididos entre o gozo hedonista de ir às compras e a culpa pelo excesso e fugacidade [...], o discurso da sustentabilidade oferece o alento indulgente: não há necessidade de reduzir, basta saber escolher! A fórmula, portanto, se inverteu: se o apelo inicial era pela redução e boicote, agora a orientação é consumir para salvar. (Guimarães Jr., 2011, p. 260)

Mas nem sempre o papel de juiz deve bastar para o consumidor. Por vezes até paira sobre ele a acusação devido a comportamentos suspeitos ou inadequados, criticados implicitamente em campanhas que se pretendem educativas ou de incentivo à cidadania, mas que acabam por constranger o consumidor a arcar pelos custos do risco ambiental com a mudança de seus próprios comportamentos. Com isso, o peso da responsabilidade por atitudes sustentáveis é desviado da cadeia produtiva das empresas e recai nos ombros dos clientes; culpa-se "individualmente o consumidor pelos impactos ambientais de seu consumo” (Guimarães Jr., 2011, p. 250). Essa estratégia é particularmente irônica nos casos de produtos que ocultam suas próprias ações ante uma fachada verdejante. Essa inusitada transferência de responsabilidade pelos impactos da cadeia produtiva nas costas (e custos) do consumidor envolve uma paradoxal estratégia de agendamento: mais que simples construção ou eco de uma agenda midiática (Silva, 2011, p. 100), trata-se da sugestão de comportamentos para os agentes consumidores. Assim, o cliente sustenta a sustentabilidade e ainda ecoa as pretensas preocupações ambientais de empresas que evitam a responsabilidade por suas cadeias produtivas. Dessa maneira, além de equalizar sua imagem com os ecos da agenda socioambiental difundida midiaticamente (Silva, 2011, p. 100), as empresas podem construir uma fachada de preocupação ecológica parasitando o esforço

1. Para saber mais sobre as iniciativas da organização no combate a campanhas publicitárias que disfarçam preocupações ambientais: http://stopgreenwash.org 
de seus consumidores, instados a mudar suas práticas de consumo para que o modelo de produção não precise ser afetado.

\section{METODOLOGIA: ANÁLISE DE DISCURSO CRÍTICA E AGENDAMENTO}

Para avaliar como as embalagens de açúcar apresentam ao público imagens da natureza, informações sobre o controle de suas cadeias de produção ou recomendações de medidas sustentáveis que deveriam ser seguidas pelo público - uma responsabilidade nem sempre compartilhada pelos próprios produtores - esta pesquisa coletou embalagens entre 2011 e 2012, em diversos estabelecimentos comerciais localizados na cidade de São Paulo. Foi adotado um método de coleta por "amostra típica" (Laville; Dionne, 1999, p. 170), selecionando as embalagens de açúcar que trouxessem a temática da sustentabilidade em sua apresentação visual e que fossem disponibilizadas para o consumidor final por estabelecimentos comerciais gratuitamente - de forma a desatrelar a sustentabilidade como marca de distinção que justificaria um custo a mais, como já discutido anteriormente, mas que não é foco da presente pesquisa. Esse método de amostragem permitiu selecionar as marcas Native, Guarani e União, que apresentavam diversas embalagens com essa temática "verde".

A seguir, foi realizada uma análise descritiva dos elementos imagéticos e textuais presentes nessas embalagens que se relacionassem à temática da sustentabilidade. Essa metodologia de descrição de conteúdos relativos a práticas de sustentabilidade em imagens publicitárias alinha-se à adotada por Calazans, Lucian, Izidio e Cavalcanti (2014), mas focando na análise particular desta pesquisa na presença de elementos que apresentem uma ancoragem verificável (como a presença de selos de certificação) dos conteúdos que evocam o meio ambiente e sugerem sua preservação em práticas sustentáveis dessas próprias marcas.

Para isso, esta pesquisa fundamenta-se na metodologia proposta por Fairclough (1997) para sua Análise de Discurso Crítica (ADC), que procura avaliar as relações dialéticas e as tensões entre discursos - linguísticos e visuais - e elementos das práticas sociais de que tratam ou em que se fundamentam (Fairclough, 2003, p. 205). A ADC pretende apontar as conexões entre linguagem, ideologia e poder, reunindo a análise linguística, sociologia e política. É uma forma de engajar as ciências sociais na emancipação humana, a partir da exploração das contradições, pressuposições e fundamentações dos discursos (Chouliaraki; Fairclough, 1999). Nessa concepção, discurso é tanto uma estrutura condicionante quanto um modo de ação e representação social.

Um dos principais teóricos dessa linha de análise de discurso, Fairclough (1992, p. 92) procura desconstruir as funções ideológicas de pressuposições, estereótipos e sensos-comuns que dissimulam suas origens e interesses. Como tratam de um "terreno comum" (Fairclough, 2003, p. 55) a partir do qual as construções discursivas podem ser edificadas, não se pode esquecer que se tratam também de uma arena em disputa, principalmente as "pressuposições valorativas", que tratam do que é bom, adequado ou desejado. Ao analisar os pressupostos das embalagens de açúcar dessa pesquisa procura-se, assim, avaliar os mecanismos de "legitimação" (Resende; Ramalho, 2006, p. 50) que tentam naturalizar uma relação mais ou menos assimétrica de poder posicionando o destinatário das mensagens das embalagens como alvo 
de conselhos e recomendações ou apresentando o produtor do açúcar como merecedor de reconhecimento por sua certificação de boas práticas.

Além disso, a análise das embalagens também revela como se realiza a "determinação e policiamento de agendas" (Fairclough, 2001, p. 196), definindo papéis e temas para o debate público: além de definir o tema da sustentabilidade como algo que merece atenção (por seu destaque nas embalagens), o consumidor pode ser um avaliador ativo das certificações, quando as embalagens assumem o ônus da prova de suas reivindicações. Por outro lado, os produtores de açúcar podem posicionar seu público como um interlocutor que só reage de forma passiva ao comportamento proposto. Em outras palavras, podemos considerar que o agendamento proposto pelas embalagens se desdobra tanto em propor a agenda (o tema discutido) quanto em induzir o posicionamento dos agentes (como devem atuar nesse debate).

Por fim, é necessário considerar por que algumas das marcas analisadas procuram embalar o açúcar em mensagens edificantes e edulcoradas, levando em consideração a análise de Fairclough (2001, p. 208) de que discursos de aconselhamento podem ser ao mesmo tempo suavizados e reforçados por uma "relação de solidariedade e de experiência em comum". Essas sugestões travestidas de certa familiaridade simultaneamente parecem aproximar emissor e receptor da mensagem, enquanto os posicionam em patamares marcadamente diferentes: de um lado, o emissor com a autoridade de quem sabe o que deve ser feito; do outro, o público, do qual só se espera que acate a convocação sutil.

Com métodos da análise de discurso crítica, avaliaremos a seguir a comunicação visual expressa nos sachês de açúcar das marcas escolhidas, buscando entrever o equilíbrio e a disputa entre as estratégias racionais e afetivas dos discursos sobre a sustentabilidade e a questão ambiental.

\section{ANÁLISE: SELOS, APELOS E O AGENDAMENTO DE CONSUMIDORES}

Feitos em tamanhos e materiais ligeiramente diferentes entre si, os sachês têm em comum, além dos cinco gramas de açúcar em seu conteúdo, uma disputa por espaço entre selos de certificação e imperativos ao consumidor em seus respectivos projetos gráficos (Figura 1).
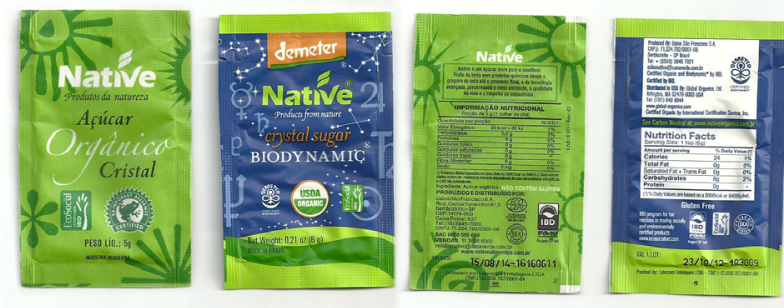

Figura 1. Embalagens do açúcar Native.

As embalagens do açúcar orgânico Native possuem um projeto gráfico bastante simples. Sobre um fundo uniforme verde com formas que lembram Sol e flores em um tom mais escuro, figuram o logotipo da marca, seguido do slogan "Produtos da natureza"; logo abaixo, uma descrição do produto - "açúcar orgânico cristal" - em tipografias com formas arredondadas e orgânicas, lembrando a caligrafia manual; em seguida, 
dois selos de certificação - o EcoSocial ${ }^{2}$ e o Rainforest Alliance ${ }^{3}$ na frente, e o Ecocert ${ }^{4}$, o IBD ${ }^{5}$ e o B.K.A ${ }^{6}$ no verso da embalagem - procuram informar o consumidor sobre as normas ambientais e de qualidade seguidas pela empresa. Um pouco diferente a embalagem para exportação coloca sobre um fundo azul constelações e zodíacos e traz os selos Demeter ${ }^{7}$, USDA Organic $^{8}$, EcoSocial, IBD, EcoCert, B.K.A e o Carbon Neutral ${ }^{9}$.

Apesar de o verde da embalagem sugerir uma associação grosseira com a questão ambiental, a comunicação da Native volta-se totalmente a expor, de maneira racional e informativa, as práticas de sustentabilidade da empresa. No verso da embalagem, um pequeno texto informa o consumidor sobre os compromissos assumidos no processo de fabricação do produto: "Native é um açúcar mais puro e saudável. Fruto da terra sem produtos químicos desde o preparo do solo até o processo final, e da tecnologia avançada, preservando o meio ambiente, a qualidade de vida e o respeito ao consumidor". Com esse breve quadro descritivo, o consumidor consegue encontrar uma explicação sintética e geral sobre os complexos objetivos por trás dos selos e certificados que estampam uma parte substancial da superfície dessa embalagem, traduzindo afetivamente distantes conceitos técnicos, que exigiriam um espaço muito maior do que o apresentado pelo sachê para serem pormenorizados.

Produtora de outros itens orgânicos além do açúcar, a empresa exibe em seu site ${ }^{10}$ mais informações sobre suas práticas ambientais e suas certificações do que sobre seus próprios produtos (Figura 2).

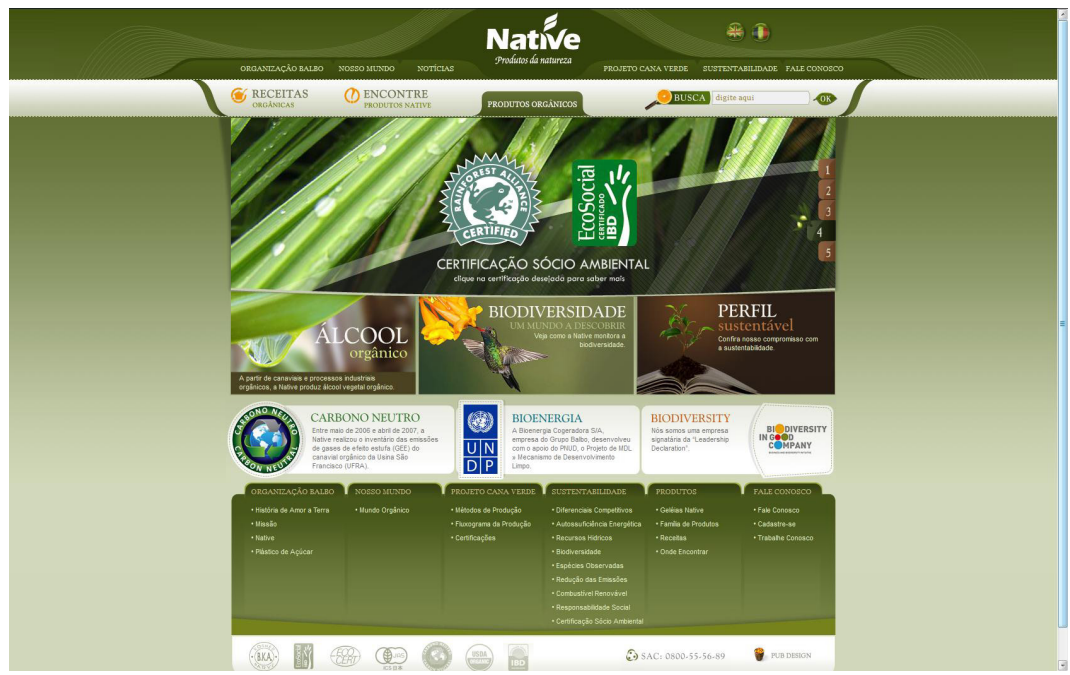

Figura 2. Site da empresa Native Alimentos, fabricante do açúcar Native.

2. Disponível em: http://ecosocialnet.com

3. Disponível em: http://rainforest-alliance.org

4. Disponível em: http://www.ecocert.com.br/

5. Disponível em: http://www.ibd.com.br/pt/Default.aspx

6. Disponível em: http://www.bka.com.br/

7. Disponível em: http://ibdsocioambiental.com.br/pt/Demeter.aspx

8. Disponível em: http://www.usda.gov/wps/portal/usda/usdahome?navid=ORGANIC CERTIFICATIO

9. Referente à neutralização da pegada de carbono. Para saber mais, acesse: http://bit. ly/206hoVo

10. Disponível em: http://www.nativealimentos.com.br 
Nas embalagens do açúcar União, por sua vez, os selos começam a perder espaço para os apelos diretos ao consumidor (Figura 3).

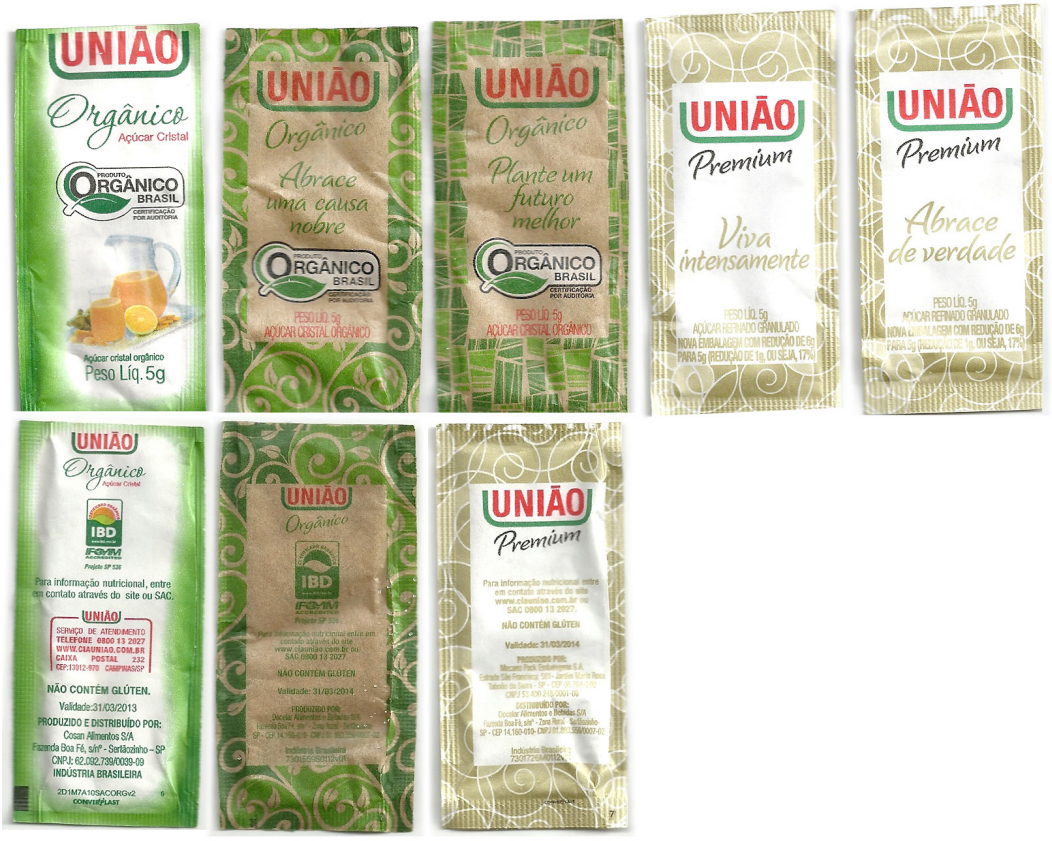

Figura 3. Embalagens do açúcar União.

Os sachês do açúcar União oferecem dois tipos de produto: o açúcar orgânico, à semelhança do açúcar Native, e o açúcar refinado, diferenciado pelo selo "Premium". Em todas as embalagens, a predileção pelas formas curvilíneas das tipografias manuscritas, associadas aos grafismos igualmente sinuosos e orgânicos - lembrando caules, folhas e gavinhas - buscam imprimir à sua apreensão visual a sensação de bem-estar e a referência à natureza. No caso do açúcar orgânico, a cor verde predomina na arte, combinando-se à tonalidade do papel da embalagem: branco ou levemente marrom, simulando o papel craft ou o papel reciclado. Na embalagem do açúcar "Premium", o verde é substituído por uma tonalidade dourada, normalmente utilizada em projetos gráficos para transmitir as ideias de requinte e sofisticação.

O selo de certificação Produto Orgânico Brasil ${ }^{11}$ é onipresente nas embalagens do açúcar orgânico União. Entretanto, como podemos ver na comparação entre a embalagem branca (à esquerda) e a marrom, o selo começa a dividir o espaço com os imperativos ao consumidor, remetendo ao ativismo ecológico: "abrace uma causa nobre"; "plante um futuro melhor”. No verso, encontramos apenas o selo IBD.

No açúcar "Premium”, por sua vez, a preocupação com o meio ambiente desvanece, o que pode ser constatado tanto pela ausência dos selos de certificação, quanto pela mudança de foco no agendamento do consumidor: os apelos transferem-se da questão ambiental para a esfera privada da vida do consumidor, incitando-o a "viver intensamente" e "abraçar de verdade". Em ambos os casos, entretanto, trata-se de ditames sobre o modo de viver do consumidor, que, embora vagos e banais, o tornariam melhor - ora para si mesmo, ora para o mundo -

11. Disponível em: http://bit.ly/2nTg0Vp 
embora a própria produção e consumo do açúcar possam eventualmente inviabilizar essa melhoria, em ambos os sentidos.

Os apelos emocionais ganham dimensão ainda maior no açúcar Guarani (Figura 4).

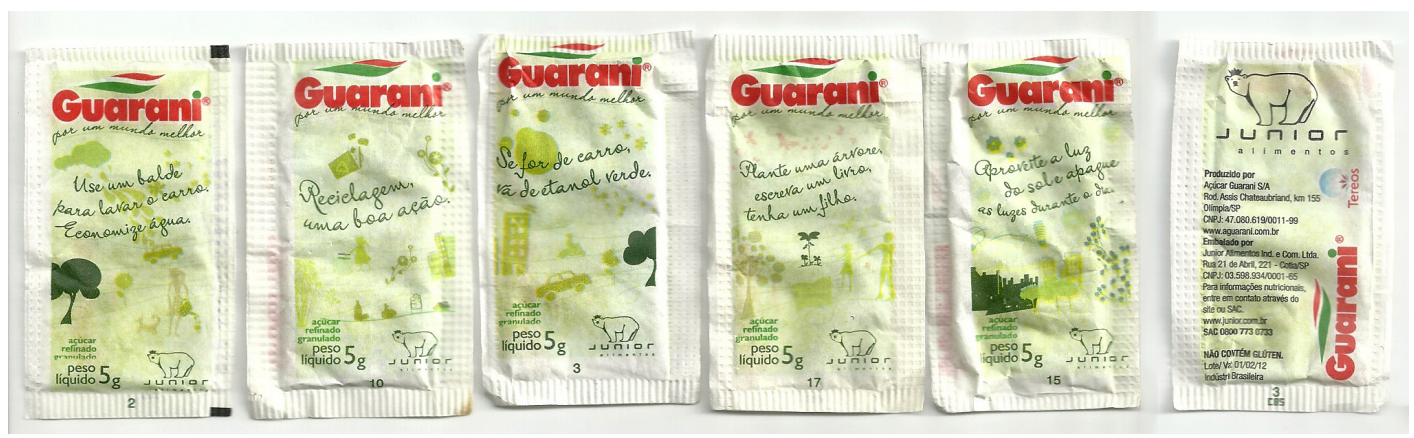

Figura 4. Embalagens do açúcar Guarani.

Aqui, o que se percebe não é só a variedade dos imperativos, mas também a ausência de qualquer selo de certificação ambiental. Tendo ao fundo uma tonalidade esverdeada salpicada de ilustrações vetoriais vagamente relacionadas a cada tema, os apelos das embalagens buscam agendar a questão ambiental, sugerindo ao consumidor uma série de ações que teoricamente - embora duvidosamente - ajudariam a lutar "por um mundo melhor" proposto pelo slogan que vemos logo abaixo do logotipo. Com clichês como "plante uma árvore, escreva um livro, tenha um filho" até frases enigmáticas como "se for de carro, vá de etanol verde" (sem esclarecer o que seria exatamente o etanol verde, por que ele é melhor e onde pode ser encontrado), o açúcar Guarani pretende dizer ao consumidor - com a leveza da tipografia e das linhas sinuosas - quais pequenas ações permitiram cumprir a complexa tarefa de melhorar o mundo $^{12}$. A empresa não se preocupa, entretanto, em esclarecer o que está fazendo em prol desse mesmo objetivo: incitando o consumidor a assumir o compromisso da sustentabilidade, omite a sua parte na aliança "por um mundo melhor".

\section{CONCLUSÃO: QUEM SUSTENTA A SUSTENTABILIDADE?}

A certificação socioambiental tornou-se uma necessidade devido à multiplicação de produtos que oferecem ao consumidor uma imagem de responsabilidade sem preocupar-se realmente em transformar práticas danosas, ou que só atrelam seus produtos com uma relação obscura com a natureza (Dias, 2009, p. 149). O greenwashing literalmente pretende uma "lavagem verde" das mercadorias suspeitas de impactos ecológicos negativos, pintando com tons esmeralda o papel reciclado que envolve produtos sem uma verdadeira preocupação ambiental - ou cuja consciência nunca chegou à prática (Santos, 2009, p. 157).

Dessa forma, não surpreende encontrar uma disputa pela representação de marcas social e ambientalmente conscientes mesmo entre os pequenos pacotinhos de açúcar distribuídos para consumidores em bares, lanchonetes e cafeterias. Além da tonalidade

12. As outras frases presentes nas embalagens recomendam: "Use um balde para lavar o carro. Economize água”; “Reciclagem, uma boa ação”; “Aproveite a luz do sol e apague as luzes durante o dia”. 
verde onipresente nas marcas analisadas, União Orgânico apresenta certificados ambientais como Produto Orgânico Brasil, IBD e IFOAM; os últimos dois também estão presentes em Native, somados ao certificado EcoSocial, da mesma IBD, e os selos da Rainforest Alliance e do EcoCert. Os slogans de cada produto constroem uma imagem de "produtos da natureza", como o da Native - que também apresenta um curto texto que o descreve como o "açúcar mais puro e saudável", "fruto da terra sem produtos químicos", "preservando o meio ambiente, a qualidade de vida e o respeito ao consumidor". Entretanto, o slogan "Guarani por um mundo melhor" acaba não encontrando base em qualquer certificação em sua própria embalagem esverdeada. Essa marca só ecoa a estratégia de usar frases motivacionais - empregada pela União - acrescentando uma tonalidade verde ao recomendar a seu consumidor que "Use um balde para lavar o carro. Economize água", ou "Se for de carro, vá de etanol verde". Também sugere "Reciclagem, uma boa ação", sem explicar se utiliza dessas práticas na produção de sua própria embalagem.

Com essa estratégia, o peso da responsabilidade política e empresarial acaba terceirizado para o indivíduo; sustentando a sustentabilidade, paga mais por um produto "verde", arcando com o custo dessa escolha ética. Esse fardo é pulverizado em milhares de pequenos pacotes - cada um deles carrega a responsabilidade pela produção do item de consumo e o joga para o consumidor final. Até mesmo uma singela embalagem de açúcar pode mostrar aos seus consumidores os certificados de manejo sustentável de sua cadeia de produção, entregando ao bolso do consumidor a tarefa de acolher o custo da opção mais verde. Obviamente, o consumidor não deve permanecer isento de responsabilidade pelos impactos da circulação de mercadorias que deseje possuir ou utilizar mas tampouco é o único responsável pelos efeitos ambientais negativos, nem deve arcar com o maior peso, imposto ou sugerido por empresas que se beneficiam desse comércio.

Por fim, os casos aqui analisados evidenciam a necessidade de que as empresas garantam a transparência sobre seus processos, ao invés de apenas constranger seus consumidores a tomarem atitudes pretensamente mais sustentáveis como lavar o carro com pouca água ou usar etanol no lugar da gasolina - quando pouco se sabe sobre o manejo hídrico ou o uso de queimadas nas lavouras da cana que agora é oferecida em pequenos pacotinhos tingidos de verde, embalados em bons conselhos.

\section{REFERÊNCIAS}

CALAZANS, J.; LUCIAN, R.; IZIDIO, A. R.; CAVALCANTI, G. K. Uma análise de conteúdo de peças publicitárias de marcas consideradas sustentáveis em paralelo com fatores importantes na decisão de compra. Signos do Consumo, São Paulo, v. 6, n. 1, p. 93-107, 2014. Disponível em: <http://bit.ly/2mZXo4V>. Acesso em: 7 out. 2015.

CHOULIARAKI, L.; FAIRCLOUGH, N. Discourse in late modernity: rethinking critical discourse analysis. Edinburgh: Edinburgh University Press, 1999.

CNI. Empresas enfrentam dificuldades no licenciamento ambiental. Sondagem especial da Confederação Nacional da Indústria - CNI, São Paulo, ano 5, n. 2, p. 7, 2007. Disponível em: <http://bit.ly/2mZOa8z>. Acesso em: 24 mar. 2017.

Meio Ambiente: maioria das indústrias faz gestão ambiental. Sondagem especial da Confederação Nacional da Indústria - CNI, São Paulo, ano 8, n. 2, p. 3, 2010. Disponível em: <http://bit.ly/2oevqTK>. Acesso em: 24 mar. 2017. 
DIAS, R. Gestão ambiental: responsabilidade social e sustentabilidade. São Paulo: Atlas, 2009.

ECHEGARAY, F. É sustentável o atual modelo de comunicação em sustentabilidade? In: KUNSCH, M. M. K.; OLIVEIRA, I. L. (Orgs.). A comunicação na gestão da sustentabilidade das organizações. São Paulo: Difusão, 2009.

FAIRCLOUGH, N. Language and power. London: Longman, 1992.

. Critical discourse analysis. London: Longman, 1997.

. Discurso e mudança social. Brasília, DF: Editora da Universidade de Brasília, 2001.

2003.

Analysing discourse: textual analysis for social research. New York: Routledge,

GUIMARÃES JR., I. S. De volta ao mundo das ideias: o fetichismo ambiental no discurso midiático da sustentabilidade. Comunicação \& Sociedade, São Paulo, v. 33, n. 56, p. 233263, 2011. Disponível em: <http://bit.ly/2nwv2D5>. Acesso em: 30 ago. 2012.

GREENPEACE. BP wins coveted 'emerald paintbrush' award for worst greenwash of 2008. 22 dic. 2008. Disponível em: < http://bit.ly/2ogWRQc>. Acesso em: 30 ago. 2012.

LAVILLE, C.; DIONNE, J. A construção do saber: manual de metodologia da pesquisa em ciências humanas. Porto Alegre: Artmed, 1999.

LOUETTE, A. Gestão do conhecimento: compêndio para a sustentabilidade: ferramentas de gestão de responsabilidade socioambiental. São Paulo: Antakarana Cultura Arte e Ciência, 2007.

RESENDE, V.; RAMALHO, V. Análise de discurso crítica. São Paulo: Contexto, 2006.

SANTOS, P.B. Comunicação e marketing no contexto da sustentabilidade dos negócios. In: KUNSCH, M. M. K.; OLIVEIRA, I. L. (Orgs.). A comunicação na gestão da sustentabilidade das organizações. São Paulo: Difusão, 2009.

SILVA, E. A. O peso das palavras, o choque dos ideais: uma análise crítica dos Indicadores de Sustentabilidade como critérios para a Gestão da Comunicação Organizacional. 2011. Tese (Doutorado em Ciências da Comunicação) - Escola de Comunicações e Artes, Universidade de São Paulo, São Paulo, 2011. Disponível em: <http://bit.ly/2oeaQTx>. Acesso em: 30 ago. 2012.

SROUR, R. H. Por que empresas eticamente orientadas? Organicom, São Paulo, v. 5, n. 8, p. 59-67, 2008. Disponível em: <http://bit.ly/2nwEOVO>. Acesso em: 30 ago. 2012. 